\title{
Anti-corrosion systems in vehicles for the transportation and application of fertilizers
}

\author{
J. Votava, M. Jukl, A. Polcar*, V. Kumbár, P. Dostál \\ Department of Technology and Automobile Transport, Faculty of AgriSciences, Mendel University in Brno, \\ Zemědělská 1665/1, 61300 Brno, Czech Republic
}

Received 23 January 2017, received in revised form 5 June 2017, accepted 7 March 2018

\begin{abstract}
This article deals with monitoring the corrosive degradation rate of zinc and duplex coatings, usable in technical practice as anti-corrosion protection in tanks for the transportation and application of industrial fertilizers and manure. Based on long-term results, samples of anticorrosive coatings for laboratory testing are prepared. The selected anticorrosive coatings are designed specifically to increase the corrosion resistance of tanks with considerable corrosion load. To compare the anti-corrosion effect, classic hot-dip galvanizing and a duplex system were chosen, and a synthetic urethane alkyd coating was used as an organic substrate. The prepared samples were subjected to metallographic tests (measuring the thickness of the anticorrosive system in the longitudinal section of the sample) and evaluation of the microstructure in the hot zinc coating. However, the essential analysis is focused on corrosion degradation in the salt mist environment according to CSN ISO 9227 (the NSS method). Based on the results of the comparison of anti-corrosion systems using salt spray, the duplex systems clearly demonstrated a significantly higher corrosion resistance than a single inorganic metallic coating.
\end{abstract}

K e y w ords: hot-dip galvanizing, duplex coating, corrosion rate, protective coating thickness

\section{Introduction}

The vast majority of agricultural machinery is made of steel parts-components. For this reason, it is necessary to realize the importance of anti-corrosion protection, and significantly extend the service life of the machinery through proper application. A classic example of this is machines used for the application of manure or industrial fertilizers. Because these are nitrogen-containing substances with a significant amount of salt, electrochemical corrosion is greatly accelerated due to the humidity.

The aggressive effect of manure on the coating of the manure tank is proven by non-destructive testing with a digital ultrasonic thickness gauge UTG-141D (Tigre, China). Two structurally identical NTF-15NV tanks were selected as samples, which served the same purpose (transportation of manure to the applicator on the field), see Fig. 1.

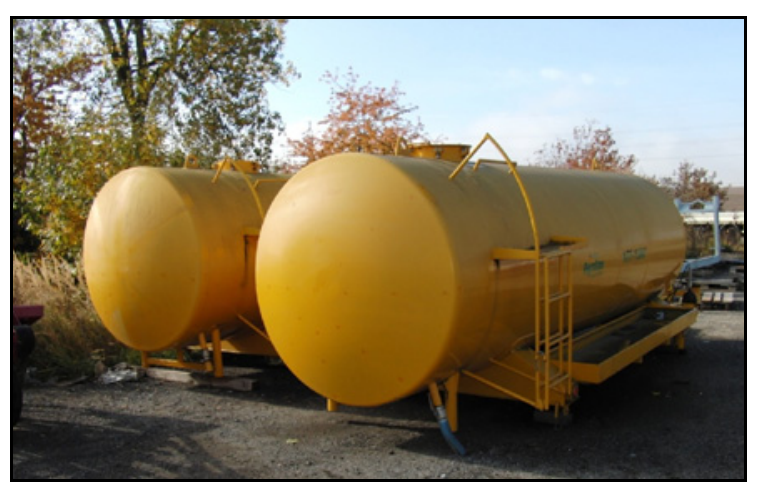

Fig. 1. NTF-15NV tanks used for testing.

The tanks were produced at an interval of two years, but were otherwise identical. The tanks were 2 and 4 years old. The tests were carried out in col-

*Corresponding author: tel.: +420 545132 123; e-mail address: adam.polcar@mendelu.cz 


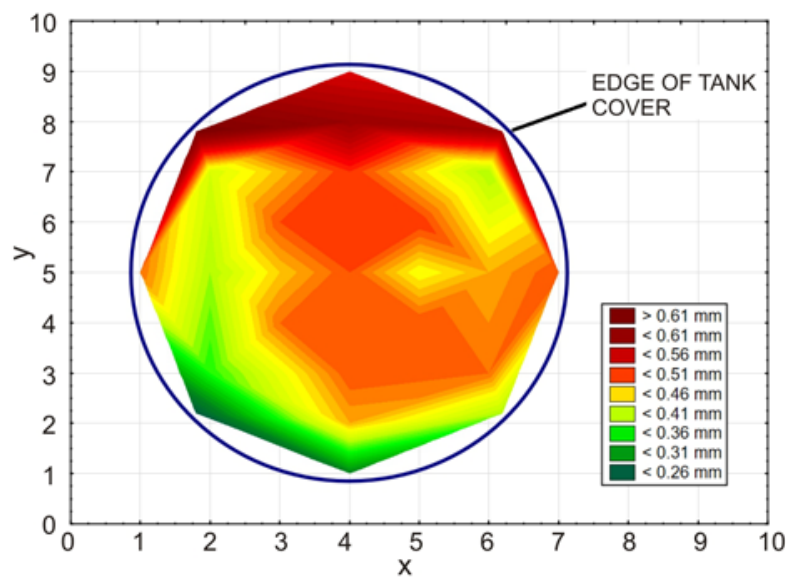

Fig. 2. Measured material loss on the front lid of the manure tank after two years of operation.

laboration with AgroStar cisterny, s.r.o (Velká Bíteš, Czech Republic). Several measurement points were chosen on the tank lid for the test. The lid of the tank is most affected by corrosion, therefore having the greatest loss of material. The results of the tank lid material loss measurement after two years of operation are shown in Fig. 2.

As the comparison of the measured values and Fig. 2 shows, there is an average of $0.5 \mathrm{~mm}$ of material loss on the front lid of the manure tank after two years of operation. Subsequent statistical testing using the $t$-test showed that this difference is statistically highly significant $(p<0.001)$. The graph also shows that the greatest material loss occurs on the upper edges of the lid. It is in these areas that the lid is most affected by the liquid and humidity during the dynamic movement of the tank, namely during its transportation.

The corrosive degradation rate can be eliminated using organic (coatings) or inorganic (metal coatings) systems, which must be applied on a suitable anchor profile without signs of corrosion $[1,2]$. Anti-corrosion protection with hot-dip galvanizing has become a very popular and widely used method in today's agricultural production [3]. Its popularity lies in the low cost of the technology, as well as its speed and reliability. An applied zinc coating is becoming the standard primarily for high volume tanks, where it often forms the underlying anchor profile for the next coating layer. These duplex systems guarantee effective protection of the given component, primarily due to the integrity and homogeneity of the anti-corrosion system as a whole. Duplex systems guarantee the isolation of the metal object from the external environment, and they also increase the protection with anti-corrosion pigments.

An important aspect of the matter is the choice of a suitable organic coating on hot-dip galvanized zinc. The standards are synthetic systems based on alkyd or alkyduretane resins. In technical practice, two-component polyurethane anticorrosion paints are also being used. The main advantage is resistance in a chemically aggressive environment $[4,5]$.

Since the protection by organic coatings consists in creating a barrier between the base material and ambient moisture [1], the composition of anticorrosive pigments and fillers in the anticorrosive substrate has a decisive influence on its functional life. Zinc nanoparticles have a great potential. These are chemical compounds of $\mathrm{ZnO}, \mathrm{ZnCO}_{3}$ and others. Many of these compounds are synthetically manufactured and used in industry. The current trend is to apply nanoparticles of these compounds again to enhance the anticorrosion resistance of the coating $[6,7]$.

The main driving force in the development of organic-inorganic hybrid based on siloxanes to prevent corrosion was the search for potential candidates to substitute environmentally unfriendly chromate surface treatments for metallic substrates [8].

However, the corrosion protection area is largely limited by the ecological parameters of used coating systems. For this reason, there is an increasing spread of water-borne materials. These anticorrosion systems have, in addition to easy application, primarily the ecological potential in the form of a reduced amount of organic emission volatile substances in paint. Non-flammability and reduced ventilation requirements also contribute to the expansion of these anticorrosive systems. For this reason, in the agricultural operation there are used the systems, the binders of which have the character of dispersions, emulsions or combinations of them [9-11].

The presented publication in the introductory section monitors tanks used mainly for the transport of farm and industrial fertilizers.

\section{Material and methods}

The main objective of this article is monitoring the corrosive degradation rate of zinc and duplex coatings, usable in technical practice as anti-corrosion protection in tanks for the transportation and application of industrial fertilizers and manure. To compare the anti-corrosion effect, classic hot-dip galvanizing and a duplex system were chosen, and a synthetic urethane alkyd coating was used as an organic substrate.

The material selected for all protection systems was a $160 \times 65 \times 1 \mathrm{~mm}^{3}$ steel sheet 11323 .

Hot-dip galvanizing: The galvanizing was carried out in a galvanizing plant. The immersion time of the samples was set to $120 \mathrm{~s}$. After the samples were removed from the molten zinc bath, they were slowly cooled in open air. The thickness of the applied zinc substrate is greatly dependent on the immersion time of the component. According to the experimental mea- 
Table 1. Alkyduretan synthetic anticorrosion system

\begin{tabular}{ll}
\hline Chemical parameters & Mechanical parameters \\
\hline Non-volatile sub. dry matter: $40-42 \mathrm{wt} . \%$ & Tearing tests: $4.3 \mathrm{MPa}$ \\
VOC: $0.42 \mathrm{~kg} \mathrm{~kg}^{-1}$ & Digging test: $2.1 \mathrm{~mm}$ up to the first tear \\
Density: $1.20 \mathrm{~g} \mathrm{~cm}^{-3}$ & Bend test: bending pin $\varnothing 15 \mathrm{~mm}$ \\
\hline
\end{tabular}

surement, the time of $120 \mathrm{~s}$ corresponds with a coating thickness of about $65 \mu \mathrm{m}$ in the given sample.

Alkyduretan synthetic anticorrosion system: It is an anticorrosion system for protection of metallic parts intended for conditions with increased risk of chemical burden. The technical parameters are shown in Table 1.

Duplex protection: To compare the rate of corrosion, a urethane alkyd coating system was applied on the zinc coating. The application was performed on the base material with an air spray gun at an ambient temperature of $22^{\circ} \mathrm{C}$ in two layers, with an interval of at least 4 hours between the applications of the second coating. The main advantage is the sealing of the pores of the zinc layer and the insulation of the metallic coating from the external environment.

Four sets of samples were prepared from each type of anti-corrosion protection, on which the following properties of the passivation coating were evaluated:

- Analysis and measurement of the passivation layer with a Neophot 21 (Carl Zeiss, Germany) metallographic microscope.

- Thickness measurement using a non-destructive magnetic induction method.

The testing of the corrosion resistance of individual systems was conducted in a salt spray environment according to [12].

The experimental results were processed and statistical analysis was performed with the software Statistica version $12 \mathrm{CZ}$ (Statsoft, USA).

\section{Results and discussion}

\subsection{Analysis of the thickness of the applied anti-corrosion layer using metallographic sections}

One of the decisive factors affecting the durability of the anti-corrosion protection of zinc and other coatings is their thickness. Based on its research, the Association of Czech and Slovak Galvanizers indicates corrosion ranging between $0.64-1.57 \mu \mathrm{m}$ per year, depending on the environment. However, these values represent corrosion for normal climatic conditions. The thickness of the protective coating is usually in the range of $30-50 \mu \mathrm{m}$. This amount of applied zinc corresponds with an average value of $0.4-0.8 \mathrm{~kg} \mathrm{~m}^{-2}$.

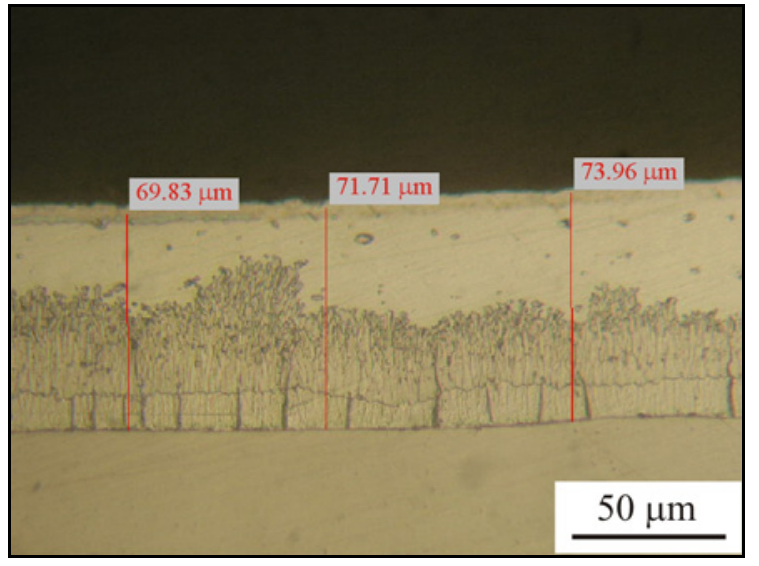

Fig. 3. Anti-corrosion coating formed by hot-dip galvanizing.

Metallographic specimens were prepared for measuring the thickness of the passivation coating. The value of the applied coating was then subtracted using the program analySIS (Olympus DP-Soft, Japan), with an accuracy of $1 \mu \mathrm{m}$. For objectivity reasons, 3 samples from each coating were selected, whereas five measured values were subtracted from each of them. The average thickness of the applied coating is shown in Fig. 3.

The thickness of the metal coating is clearly visible in the metallographic sample, see Fig. 3. In hot-dip galvanizing we can observe intermetallic phases, which grow through to the very top of the coating. This is the formation of outbursts. In terms of anti-corrosion protection, this is an undesirable effect that reduces the durability of the coating. Metal coating plus anticorrosion protection with a coating system represent an increase in the thickness of the anti-corrosion system by an addition of approximately $45 \mu \mathrm{m}$.

A very easy analysis of the coating thickness is performed using a probe based on the principle of eddy currents. The standard evaluation unit Elcometer 456 (Elcometer, UK) was used for our experiment. The thickness is measured on a cured coating. This is a non-destructive test that can be applied to ferromagnetic substrates, the condition being a non-ferromagnetic coating layer. The average thickness values of the tested anti-corrosion systems are shown in Table 2. 
Ta ble 2. Thickness values of tested anti-corrosion systems

\begin{tabular}{|c|c|c|c|c|c|c|c|c|}
\hline \multirow{2}{*}{ Method of measurement } & \multirow{2}{*}{ Tested coat } & \multicolumn{5}{|c|}{ Number of measurement } & \multirow{2}{*}{ Mean } & \multirow{2}{*}{$\begin{array}{l}\text { Standard } \\
\text { deviation }\end{array}$} \\
\hline & & 1 & 2 & 3 & 4 & 5 & & \\
\hline \multirow[t]{3}{*}{ Metallurgical measurement } & Zinc coat $(\mu \mathrm{m})$ & 66 & 75 & 78 & 70 & 69 & 71.6 & 4.83 \\
\hline & Lacquer system $(\mu \mathrm{m})$ & 32 & 38 & 34 & 39 & 34 & 35.4 & 2.97 \\
\hline & Duplex system ( $\mu \mathrm{m})$ & 98 & 113 & 112 & 109 & 103 & 107.0 & 6.36 \\
\hline \multirow[t]{2}{*}{ Measurement by Elcometer 456} & Zinc coat $(\mu \mathrm{m})$ & 61 & 75 & 65 & 59 & 67 & 65.4 & 6.23 \\
\hline & Duplex system ( $\mu \mathrm{m})$ & 93 & 105 & 97 & 112 & 96 & 100.6 & 7.77 \\
\hline
\end{tabular}

\subsection{Evaluation of corrosion resistance of the used coatings}

The corrosion resistance test of individual inorganic and duplex coating systems was performed by standard procedure according to [12] - Neutral Salt Spray Test (NSS method). Since it is a very aggressive continuous test, no long-term cyclical tests have been performed, e.g. with different chemical composition of the test environment. As mentioned in the introduction, the tests are focused on the analysis and monitoring of anticorrosive systems designed for tanks carrying mainly farmyard fertilizers. For this reason, sodium chloride was selected as the main initiator of corrosion. Industrial fertilizers formed only a minor part of the transport, even in the monitored tanks. The Liebisch S400M-TR (Liebisch, Germany) chamber was used for the experiment.

Test parameters:

- Ambient temperature surrounding the test samples $35 \pm 2{ }^{\circ} \mathrm{C}$.

- Concentration of sodium chloride in the spraying medium $50 \pm 5 \mathrm{~g} \mathrm{l}^{-1}$.

- $\mathrm{pH}$ of the salt solution $6.5-7.2$.

- The duration of the test in the first stage was set at the following intervals: $1,2,3,5,7,10,20$, and 30 days. Based on the daily visual observation, the given intervals may vary depending on the rate of corrosion.

The objective of the anti-corrosion test is to compare the resistance of a zinc substrate in a $\mathrm{NaCl}$ environment with the same coating, which is subsequently treated with a urethane alkyd coating system. The monitoring of the tested samples is mostly focused on the beginning of the corrosion development in the sample's steel substrate. An early manifestation of the degradation process of the steel part is red rust, which appears on the surface of the part. This is an outburst from the anti-corrosion barrier, leaving nothing to prevent the corrosion reaction. The main objective of accelerated corrosion tests is to determine the durability of protective coatings before their violation.

The pitting corrosion indicates the localized place from where the corrosion continues to grow. As Fig. 4a shows, the zinc coating is transformed into zinc hy-
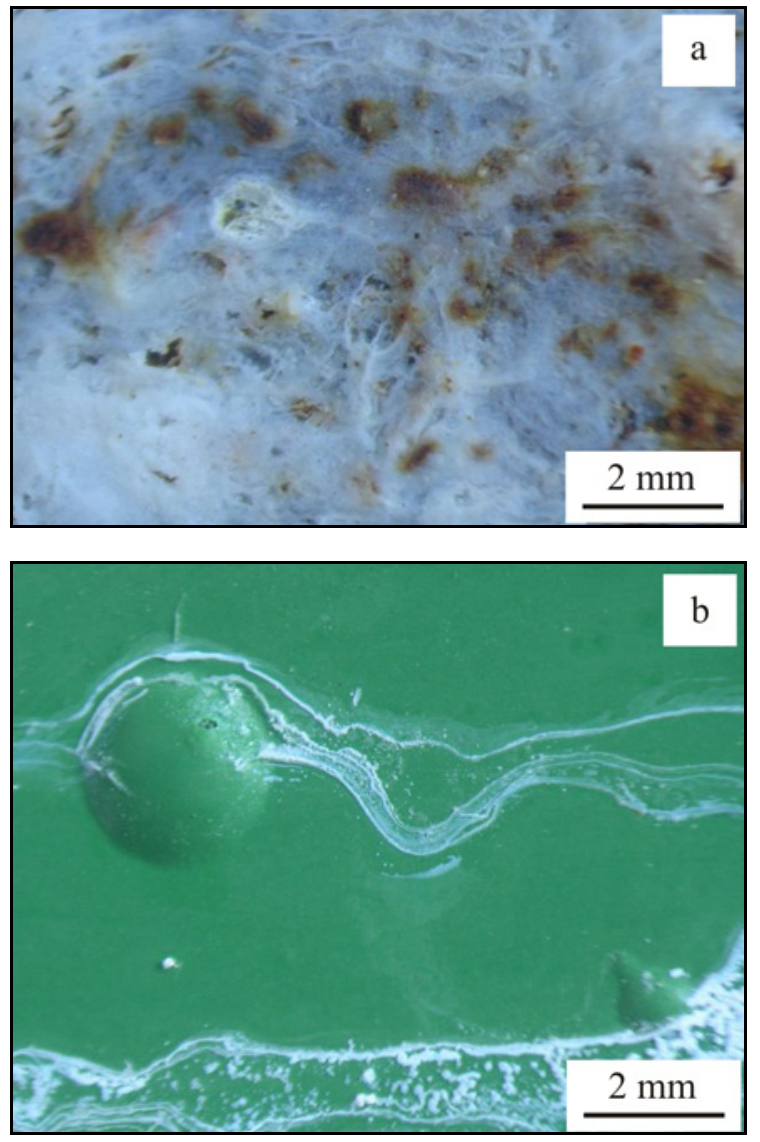

Fig. 4a,b. Pitting corrosion in anti-corrosion systems after 10 days in a salt spray.

droxide products, which can no longer resist the increased corrosion pressure. Localized places with depleted zinc ions are formed, resulting in the corrosion of the base steel material. The test showed a resistance of only 7 days until the emergence of localized corrosion.

In the duplex protection system (zinc + urethane alkyd coating system), see Fig. 4b, we can see a sealing of the zinc coating and therefore a significant deceleration of the corrosion reaction. According to studies [13], the functional mechanism of depolarization of du- 
Table 3. Results of Canonical Correlations

\begin{tabular}{lcccc}
\hline Variables & Canonical Correlations & $R$-squared & $F$-value & Prob. level $(p$-value $)$ \\
\hline Hot-dip galvanizing & 0.985169 & 0.970559 & 197.8 & 0.000008 \\
DUPLEX SYSTEM & 0.951619 & 0.905579 & 57.55 & 0.000273 \\
\hline
\end{tabular}

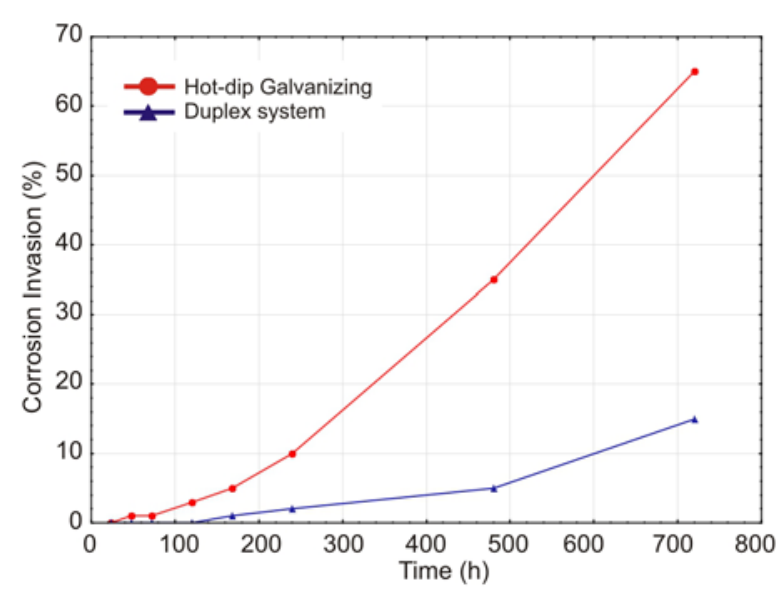

Fig. 5. Rate of corrosion reaction in both systems.

plex systems can be confirmed. Thus, signs of initial corrosion can be recorded in a wider corrosion load interval. The initial stage consists of the blistering of the coating system. These blisters were only observed rarely after exposure to salt spray at an interval of 10 days. Even at this stage of the degradation of the top organic coat, the passivation of the zinc substrate itself still remains. For this reason, not only agricultural manufacturers are switching to the use of duplex systems.

Transformed zinc products in the form of hydroxide and zinc carbonate still function as a corrosion inhibitor. The corrosion rate of both systems is shown in Fig. 5.

As the graph shows, with the duplex system the corrosion rate of the material is slower. In galvanizing a stronger correlation dependence was observed than in the duplex system. After determining whether the dependence between the two variables is statistically significant, canonical correlation analysis is used [14]. Both the zinc and the duplex system exhibit a highly statistically significant dependence. The results of the canonical correlation analysis are presented in Table 3.

The results of the tests also clearly confirmed the effect of the thickness of the protective coating on the anti-corrosion efficiency of the given system. However, it is necessary to state that the $\mathrm{NaCl}$ environment is considerably aggressive for testing of zinc coatings. These conclusions are also stated in the publication by [15]. With hot-dip galvanizing a protective coating thickness of $64 \mu \mathrm{m}$ was achieved, which consists of $8.099 \mathrm{~g}$ of zinc on the test sample, according to the density of the zinc itself. After 14 days of exposure in a salt spray chamber, approximately $25 \%$ of the surface was covered in red rust. After the following removal (exposure time of 30 days), approximately $65 \%$ of the surface was affected. In samples containing the duplex system (zinc $64 \mu \mathrm{m}+$ urethane alkyd coating system $35 \mu \mathrm{m}$ ), approximately $15 \%$ of the surface was affected (Fig. 5). Seré et al. [16] also compared hot-dip galvanizing with duplex systems. In his study, he compared two zinc coatings with a different chemical composition $\mathrm{Zn}-\mathrm{Al}$; these inorganic coatings were further protected by an organic waterbased polyurethane coating. Based on the results of the comparison of the anti-corrosion systems using salt spray, the duplex systems clearly demonstrated a significantly higher corrosion resistance than a single inorganic metallic coating.

The suitability of duplex systems was also confirmed in welded joints, where the duplex systems provide enhanced corrosion protection particularly in the "hot" areas (welding bead and welding material joint), as it results in better sealing of the affected area than the zinc coating. The self-healing effect was fully demonstrated when the products of zinc hydroxide continued to be protected by the base material itself until the depletion of all $\mathrm{Zn}^{+}$ions [18].

The self-healing effect was also observed in zinc coatings applied by spraying molten metal in a stream of air (metallization). The advantage of this technology is the combination of chemical elements in the molten metal (Zn-Al). Duplex systems can also be used with these coatings, because the anchoring profile of the substrate provides a good cohesive connection with the coating system. Based on the study by [17], a corrosion resistance below $20 \%$ was confirmed for these coatings after $720 \mathrm{~h}$ of exposure to salt spray. The current trend is also the use of zinc sprays supplemented with $\mathrm{Al}$ particles. These anticorrosion systems can also be used on a partially corroded surface [18].

\section{Conclusions}

Based on the corrosion tests, we can clearly conclude that duplex systems are suitable for environments with high corrosion activity. The higher purchase price of the duplex anticorrosion system (which is adequate to the input financial requirements for the production of the system) is clearly balanced by the 
extended life of the entire machine. According to the corrosion tests and the statistical evaluation, there can be stated the higher utility value of the duplex system by about $30 \%$. Unique benefits are given by the other authors in the introductory section. However, point corrosion represents an increased risk for machines transporting farmyard fertilizers. Localized pitting corrosion presents the greatest threat during the filling or emptying of all transportation equipment. The increase in pressure inside the vessel during operation means a possibility of destroying the walls and hence the entire machine. When treating a steel tank with a duplex system, this risk of point corrosion can be greatly eliminated. An organic coating system protects the integrity of the surface. For this reason, the zinc chemical products are not always removed since they passivate the zinc itself. However, in a point break of the top organic coating, the zinc itself in the given area is able to produce a sufficient amount of $\mathrm{Zn}^{+}$ions necessary to seal the area.

\section{Acknowledgement}

The research has been supported by the project TP 6/2017 "Defectoscopic Quality Assessment of Technical and Organic Materials" financed by the Internal Grant Agency FA MENDELU.

\section{References}

[1] Trethewey, K. R., Chamberlain, J.: Corrosion for Science and Engineering. 2nd Edition. Addison, Wesley Longman 1995.

[2] Marcus, P.: Corrosion Mechanisms in Theory and Practice. 2nd Edition. New York, Marcel Dekker 2002.

[3] Bardal, E.: Corrosion and Protection. 1st Edition. London, Springer 2003.
[4] Bertolini, L., Elsener, B., Pedeferri, P., Polder, R.: Corrosion of Steel in Concrete: Prevention, Diagnosis, Repair. New Jersey, Wiley-VCH 2005.

[5] Cicek, V.: Corrosion Engineering. Massachusetts, Wiley 2014.

[6] Luptáková, N., Kebisková, J., Anisimov, E., Benák, M., Pešlová, F.: In: Proceedings of 21st International Conference on Metallurgy and Materials 2012. Brno, TANGER, Ltd. 2012, p. 1521.

[7] Luptáková, N., Pešlová, F., Kliber, J.: Metalurgija, 54, 2015, p. 43.

[8] Figueira, R. B., Silva, C. J. R., Pereira, E. V. J.: J. Coat. Technol. Res., 12, 2015, p. 1. doi:10.1007/s11998-014-9595-6

[9] Wilson, A. D., Nicholson, J. W., Prosser, H. J.: Waterborne Coatings Surface Coatings. 3rd Edition. London, Elsevier Science Publishers LTD 1990.

[10] Amalvy, J. I., Aznar. A. C., Pardini O. R., Guzmán, G. A.: Corrosion, 58, 2002, p. 871. doi:10.5006/1.3287672

[11] Votava, J., Kumbár, V.: Manufacturing Technology, 17, 2017, p. 103.

[12] CSN EN ISO 9227 - Corrosion Tests in Artificial Atmospheres - Salt Spray Tests, Czech Standards Institute, 2013. (in Czech).

[13] Seré, P. R., Elsner, C. I., Di Sarli, A. R.: Corrosion Prevention and Control, 45, 1998, p. 109.

[14] Meloun, M., Militký, J.: Statistical Data Analysis: A Practical Guide. 1st Edition. New Delhi, Woodhead Publishing India PVT LTD 2011.

[15] Almeida, E., Pereira, D., Figueiredo, O.: Progress in Organic Coatings, 17, 1989, p. 175. doi:10.1016/0033-0655(89)80022-6

[16] Seré, P. R., Deyá, C., Elsner, C. I., Di Sarli, A. R.: International Journal of Adhesion and Adhesives, 50, 2014, p. 1. doi:10.1016/j.ijadhadh.2013.12.019

[17] Votava, J.: Acta Universitatis Agriculturae et Silviculturae Mendelianae Brunensis, 61, 2013, p. 1487. doi:10.11118/actaun201361051487

[18] Votava, J.: Acta Universitatis Agriculturae et Silviculturae Mendelianae Brunensis, 61, 2013, p. 1897. doi:10.11118/actaun201361061897 